\title{
The impact of political socialization on students' behavior: Empirical research in schools of Central Macedonia in Greece
}

\author{
Antonis Papaoikonomou ${ }^{1}$
}

\section{ARTICLE INFO}

Article History:

Received 03.03.2017

Received in revised form

05.05.2017

Accepted

Available online 01.07.2017

\begin{abstract}
The main purpose of this article is to present the secondary education students' points of view regarding issues that are related to their everyday reality. A link to their political socialization is attempted. At the same time, the influence of independent variables is examined, like "sex", "urbanity", "performance" and "parents' occupation". The final conclusion shows that even though the majority of students do not express intense negative feelings about different origin, sex and religion, a tendency is at sight, mainly by male students. This conclusion is also compared with the findings of the survey "EUROPE ON THE EDGE", regarding issues of difference and democratic values.
\end{abstract}

(C) 2017 IJERE. All rights reserved

Keywords:

Political socialization, students, education, Greece.

\section{INTRODUCTION}

The term political socialization refers to the process through which individuals develop a relationship with the political world and obtain the knowledge, the opinions, the values and the behavior that lead to the shaping of their political identity. Through the process of socialization, individuals obtain the sense of belonging in a society and are driven to the internalization of their national political culture. The political socialization of the individuals, as well as the integration of their principles and actions, helps them become assimilated in the political systems, thus leading to the creation of active citizens. This process of political socialization is, therefore responsible for the transmitting of a particular political culture - which is defined as "a system of attitudes, values and knowledge, adopted by the wide strata in a society" (Inglehart, 1990) from generation to generation. The common understanding of customs, traditions and heroes of every nation is interconnected within a societal system, as well as with the nature and the functions of the government.

The educational system is the major means of transmitting the knowledge and the values of every society. According to the functionalist theory, it constitutes the reproductive system of every society, shaping through its mechanisms the future citizens. As such, it will be interesting to analyze the repercussions of students' political socialization in schools with regard to the factor of 'diversity', whether this is religious or racial.

\section{THEORETICAL FRAMEWORK}

In general terms, political socialization is the transmission of political culture to new generations of citizens in a society (Almond \& Verba, 1963. Gimpel, Lay \& Schuknecht, 2003). It is the product of a mutual 'weaving' of phenomena in both macro and micro level. The basic question that has already been put forward in research related to the issue of political socialization in macro level is: how do policies transmit their values, attitudes and behavior to the masses? Furthermore, studies in micro level raise the question: how and why do individuals become citizens?

In terms of macro level, political socialization is the means by which each policy transfuses adequate norms and practices to the citizens and generally to the members of a society (Sapiro, 2004). Each policy conveys the standard patterns of thought and the actions, the laws, the norms and the traditions, such as the family, the educational system, the peer group, the mass media, the political institutions, the organizations of the community, the religion and the army (Beck \& Jennings, 1982. Marshall, 1998). The kinds of questions that are postulated in macro level focus on the way that people develop their political orientations and the practices with which the ideas of democratic institutions are transformed into realistic and functional democratic policies (Sapiro, 2004).

\footnotetext{
${ }^{1}$ Corresponding e-mail: papaoiko@sch.gr
}

Aristotle University of Thessaloniki 
In micro level, on the other hand, political socialization concerns the patterns and the processes with which individuals entangle in procedures of political development, constructing their particular relationship within the political environment in which they live (Sapiro, 2004). As a result of political socialization, individuals obtain the knowledge of the way the political system works. They internalize the political values of society and its ideology, and understand its symbols and rituals. They are informed about the role of active and passive members of the political system and are able to participate in political and civic life, accordingly.

During their socialization, individuals receive stimuli and internalize values and convictions which are related to political phenomena. These stimuli have an impact on political thought and behavior. In other words, there is a particular procedure, through which individuals come into contact with the political culture of the society in which they belong (Givalos, 2005 - Metaxas, 1976. Terlexis, 1975).

Therefore, the political behavior of the members of a society depends on the content of this procedure, which in turn influences the function of the entire political system. On the other hand, the content of the political socialization that individuals receive also depends on the political system in which this socialization develops. Thus, it becomes evident that the two parts are interrelated and interact continuously. Moreover, if it is taken into account that every political system is formed and defined by the ethics, the political values and habits of a society - elements that in turn are defined by the historic and cultural habits of this society - political socialization can be defined as the procedure of formation of political subjects; a procedure that contributes to the configuration and the transmission of political culture from one generation to another, starts from a very early age and continues throughout lifetime. In other words, since the beginning of his/her childhood the individual starts forming his/her political identity because he/she accepts the political culture of the group in which he/she belongs, while at the same time he/she constantly contributes to its reformation (Givalos, 2005. Terlexis, 1975). Taking into account this aspect of political socialization, it would be interesting to focus on the way this notion influences the formation of students' attitudes towards 'the diverse' as this is contrasted with their notion of 'the right' or the 'appropriate'. Pupils, thus, will be asked about their attitude in relation to everyday issues, such as different religion, origin and gender issues. A desideratum of this research is the quest of the internalization degree of the society patterns as far as issues that pertain to politics and social reality in general are concerned. At the same time, the impact of important factors will be examined, that is the factors of "sex", "school performance", the "urbanity" and the "professional and educational level of parents".

\section{The aim of the research}

The aim of this research is the depiction of secondary education students' points of view about 'the diverse'. The concept of 'diversity' is understood as "every attitude that comes in contrast with what they believe is normal". The questions were focused on matters of gender, religion, and origin. It is expected that the presentation of results will clarify the aspects of the pupils' political socialization but will also give prominence to topics that cause unpredictable behavior on their behalf. On a next level, a correlation will be applied among the findings, using pupils' "sex", "urbanity", "performance" and the "profession of their parents" as independent variables. Apart from that, a comparison will be attempted between the findings of the present research and those of the survey "EUROPE ON THE EDGE" in respect of issues of diversity and democratic values.

\section{METHOD}

Despite its limitations, for the examination of the research problem, the survey was considered to be the most appropriate method, as it ensured the participation of a large number of pupils. The survey was addressed to pupils from secondary schools of Central Macedonia in Greece, in particular the regions of Kilkis and Thessaloniki, so as to include the views of students from urban, semi-urban and rural areas.

The questionnaire of this study was based on two previous studies that had been conducted for similar reasons. The first was the research conducted by Professor Michalis Kelpanidis in 2012 and it concerned the examining of pupils' points of view on sits-in. The second was a research conducted by Pr. Stavrakakis and Pr. Demertzis, and it examined the young people's attitudes on different issues of their daily life (Demertzis \& Stayrakakis, 2008). Initially, a pretest research was conducted in a lyceum class so as to ascertain the pupils' attitude towards the questionnaire and to calculate the time needed to answer the questions. In general terms, the results showed a good reception of the research instrument, while the time 
did not exceed 25 minutes. Once the research was approved by the Institute of Educational Policy and instructions were given, letters were sent to the students' parents in order for them to consent to the pupils' participation. It has to be noted that all parents approved the students' participation without any objections. Of the 1,100 questionnaires that were distributed to pupils, 960 were given back. The data presented below, are from the final questionnaire.

More analytically, six schools from central Macedonia were involved: a general lyceum and a gymnasium of Thessaloniki (which is in an urban area), a vocational school from the prefecture of Kilkis, two general lyceums and a gymnasium from the prefecture of Kilkis (a semi-urban area, since the town's population is over 10,000 inhabitants) and, finally, a lyceum and a gymnasium from villages with less than 2000 inhabitants (rural areas). The precise number of pupils regarding the area where they live is presented in the following table (table 1):

Table 1. Distribution of pupils regarding the area

\begin{tabular}{lcc}
\hline & Frequency & Percentage \\
\hline Urban & 236 & 24,6 \\
Semi-urban & 509 & 53,0 \\
Rural & 215 & 22,4 \\
Total & 960 & 100,0 \\
\hline
\end{tabular}

The gender of the pupils that participated in this research is presented in the following chart (chart 1) and it shows that $54.7 \%$ are boys and $45.3 \%$ are girls:

Chart 1 . The sex of the pupils of the research

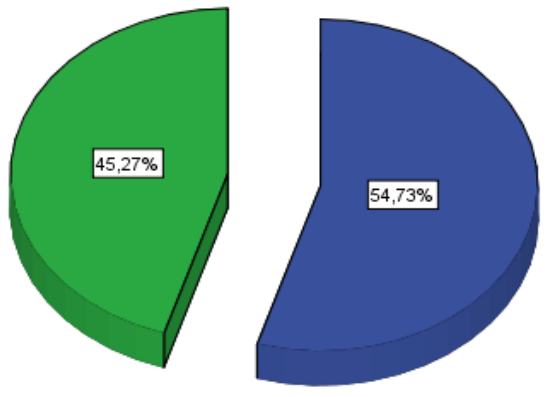

Boys Girls

As far as the pupils' ages were concerned, great variance was observed owing to the fact that only older pupils from the vocational school participated in the study. Also, due to the fact that in the particular area there is not a Second Chance School, many adults choose the vocational school in order to complete their secondary education. The ages of the pupils are presented in table 2:

Table 2. The ages of the pupils

\begin{tabular}{ccccc}
\hline & & Frequency & Percentage & $\begin{array}{c}\text { Cumulative } \\
\text { Percentage }\end{array}$ \\
\hline $\begin{array}{c}50 \\
\text { years old }\end{array}$ & to & 13 & 1,4 & 1,6 \\
23 to 17 & 258 & 26,9 & 32,5 \\
years old & & 430 & 44,8 & 84,2 \\
16 to 14 & 132 & 13,8 & 100,0 \\
years old & & 833 & 86,8 & \\
13 and below & 127 & 13,2 & \\
Total & & & & \\
Missing & & & &
\end{tabular}




\begin{tabular}{ccccc}
\hline & & Frequency & Percentage & $\begin{array}{c}\text { Cumulative } \\
\text { Percentage }\end{array}$ \\
\hline $\begin{array}{c}50 \\
\text { years old }\end{array}$ & 24 & 13 & 1,4 & 1,6 \\
23 to 17 & 258 & 26,9 & 32,5 \\
$\begin{array}{c}\text { years old } \\
16 \text { to } 14\end{array}$ & 430 & 44,8 & 84,2 \\
years old & & 132 & 13,8 & 100,0 \\
13 and below & 833 & 86,8 & \\
Total & 127 & 13,2 & \\
Missing & 960 & 100,0 & \\
Total & & & \\
\hline
\end{tabular}

Table 3 and 4 present the frequencies of the pupils according to the type of school they attend, as well as their class:

Table 3. Types of school

\begin{tabular}{ccc}
\hline & Frequency & Percentage \\
\hline Lyceum & 416 & 43,5 \\
Gymnasium & 283 & 29,6 \\
Vocational & 257 & 26,9 \\
School & & \\
Total & 956 & 100,0 \\
Missing & 9 &, 4 \\
Total & 960 & \\
\hline
\end{tabular}

Table 4. Class

\begin{tabular}{lcc}
\hline \multicolumn{1}{c}{ Class } & $\begin{array}{c}\text { Freque } \\
\text { ncy }\end{array}$ & Percentage \\
\hline A Lyceum & 217 & 23,1 \\
B Lyceum & 147 & 15,7 \\
C Lyceum & 292 & 31,1 \\
A Gymnasium & 96 & 10,2 \\
B Gymnasium & 50 & 5,3 \\
C Gymnasium & 137 & 14,6 \\
Total & 939 & 100,0 \\
Missing & 21 & \\
Total & 960 & \\
\hline
\end{tabular}

Each pupil's performance - as depicted in the final grade - will be an important independent variable for further analysis. The following chart shows that the average grade of 740 pupils is 16.09 and its standard deviation is 2,351 . It has to be noted that 220 pupils did not want to answer the questionnaire, claiming that this information is personal data and, as such, this information is irrelevant to the purpose of this research.

Chart 2. Pupils' grade 


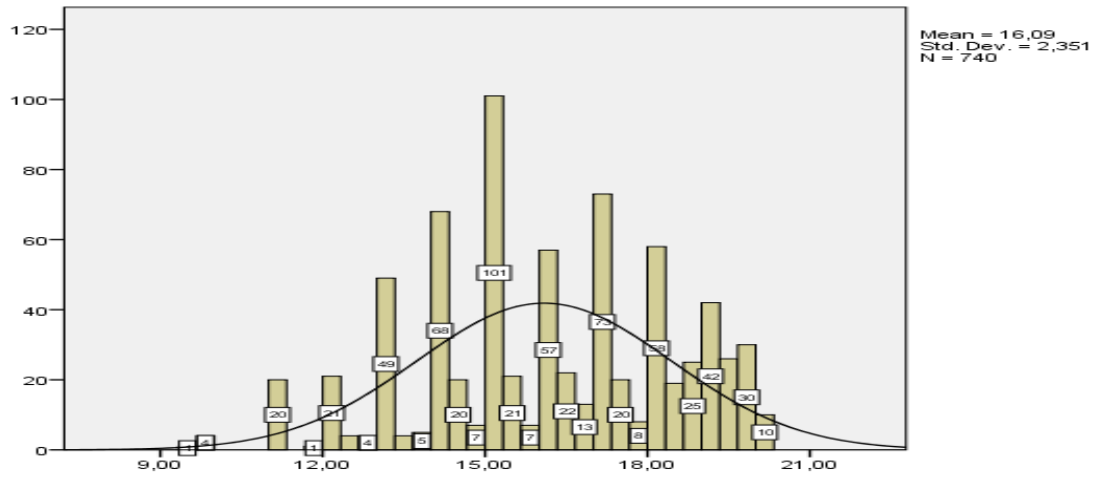

Next, some demographic data will be presented, which are considered as crucial factors in political socialization. The parents' profession was examined, as well as their educational level. Mother's and father's educational status were examined separately. Table 5 presents the frequencies of each case:

Table 5. Parents' professional position

\begin{tabular}{|c|c|c|c|c|}
\hline & \multicolumn{2}{|c|}{ Father } & \multicolumn{2}{|c|}{ Mother } \\
\hline & Frequency & Percentage & Frequency & Percentage \\
\hline Self-employed & 187 & 19,5 & 129 & 13,4 \\
\hline Freelance & 125 & 13,0 & 71 & 7,4 \\
\hline $\begin{array}{l}\text { Employer (employs up } \\
\text { to } 5 \text { persons) }\end{array}$ & 67 & 7,0 & 50 & 5,2 \\
\hline $\begin{array}{l}\text { Employer (employs } \\
\text { more than } 5 \text { persons) }\end{array}$ & 42 & 4,4 & 20 & 2,1 \\
\hline $\begin{array}{l}\text { Civil servant (lower } \\
\text { position) }\end{array}$ & 15 & 1,6 & 36 & 3,8 \\
\hline $\begin{array}{cc}\text { Private } & \text { employee } \\
\text { (lower position) } & \end{array}$ & 40 & 4,2 & 59 & 6,1 \\
\hline $\begin{array}{l}\text { Civil servant (medium } \\
\text { position) }\end{array}$ & 114 & 11,9 & 122 & 12,7 \\
\hline $\begin{array}{cc}\text { Private } & \text { employee } \\
\text { (medium position) } & \end{array}$ & 109 & 11,4 & 104 & 10,8 \\
\hline $\begin{array}{cc}\text { Private } & \text { employee } \\
\text { (senior position) } & \end{array}$ & 47 & 4,9 & 36 & 3,8 \\
\hline $\begin{array}{l}\text { Civil servant (senior } \\
\text { position) }\end{array}$ & 54 & 5,6 & 29 & 3 \\
\hline Missing & 160 & 16,7 & 304 & 31,7 \\
\hline Total & 960 & 100,0 & 960 & 100,0 \\
\hline
\end{tabular}

As far as the value 'missing cases' is concerned, this refers to the cases where either the father or the mother does not work - willingly or not. The percentage of unemployed mothers is $31.7 \%$ and of unemployed fathers is $16.7 \%$. Regarding their educational level, the majority of both parents are higher secondary education (lyceum) graduates while also a large percentage of them are holders of university and technological educational institute degrees. Educational level frequencies are presented in the following table (table 6):

Table 6. Parents' educational level.

\begin{tabular}{ccccc}
\hline & \multicolumn{2}{c}{ Father } & \multicolumn{2}{c}{ Mother } \\
\hline Up to & Frequency & Percentage & Frequency & Percentage \\
\hline $\begin{array}{l}\text { primary school } \\
\text { certificate } \\
\text { Up to }\end{array}$ & 112 & 13,2 & 40 & \\
$\begin{array}{l}\text { gymnasium } \\
\text { certificate } \\
\text { Up to }\end{array}$ & 133 & 15,7 & 137 & 16,2 \\
$\begin{array}{l}\text { lyceum } \\
\text { certificate }\end{array}$ & 288 & 34,0 & 322 & 38,2 \\
\end{tabular}




\begin{tabular}{lcccc}
$\begin{array}{c}\text { Technolo } \\
\text { gical Institute } \\
\text { degree }\end{array}$ & 196 & 23,2 & 174 & 20,6 \\
$\begin{array}{l}\text { Universit } \\
\text { y degree }\end{array}$ & 91 & 10,8 & 132 & 15,6 \\
Master's & 13 & 1,5 & 24 & 2,8 \\
PhD & 13 & 1,5 & 15 & 1,8 \\
Total & 846 & 100,0 & 844 & 100,0 \\
Missing & 114 & & 116 & \\
Total & 960 & & 960 & \\
\hline
\end{tabular}

In order to examine the reliability of the sample, Cronbach's alpha index was used. Its value appears statistically significant for the variables examined $(0,744)$. In particular, the index was calculated using the following variables:

1. Variable name: "you have negative attitude towards your fellow students about issues that are related to the origin of man".

2. Variable name: "you have a negative attitude towards your fellow students about issues that are connected with the gender".

3. Variable name: "you have a negative attitude towards your fellow students about issues that are connected with religion".

The majority of students never had a negative attitude towards their fellow students on any of the above topics. There are some minor deviations in some questions, the most important of which is the rare negative attitude (33.48\%) towards students with a different gender behavior. Also important is the finding that $18.61 \%$ of the pupils often, or very often, maintain a negative attitude towards their fellow students about issues that are connected with their nationality. The deviations and the frequencies are shown analytically in the following charts:

Graph 3. Attitudes about everyday issues.

Negative attitude due to nationality

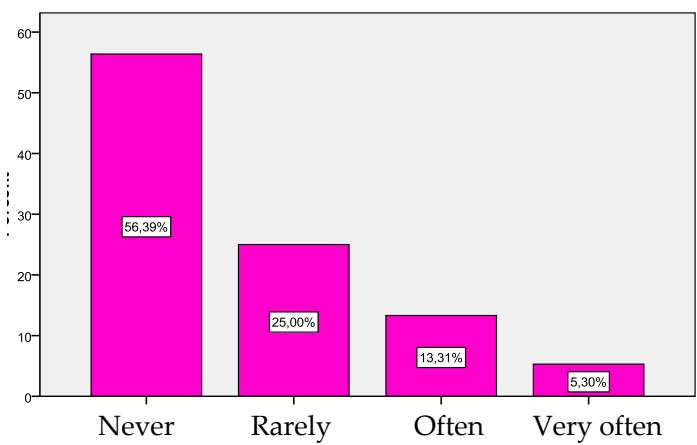

Negative attitude due to gender

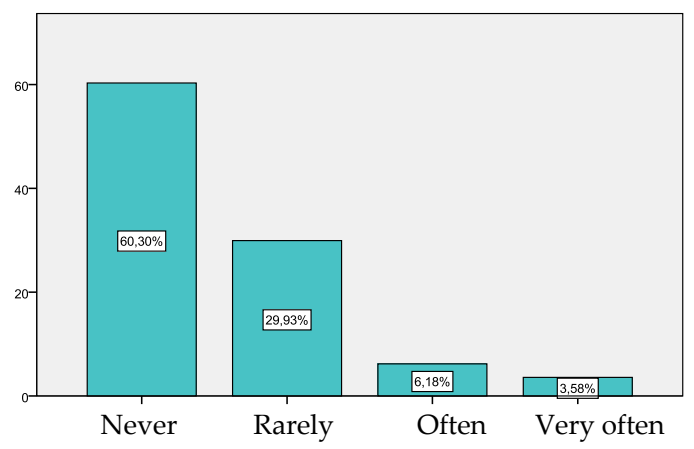

Negative attitude due to different religion

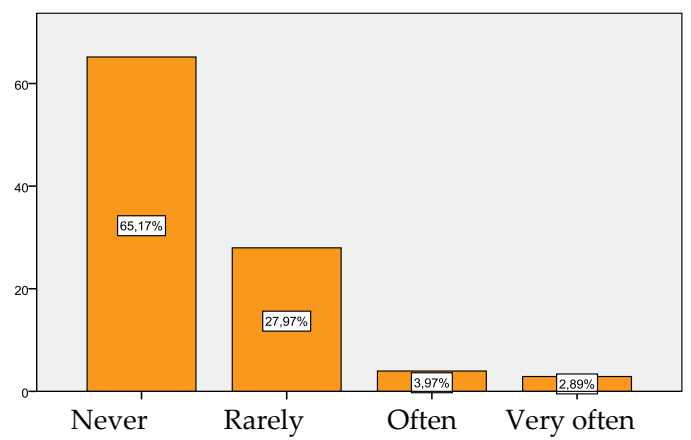

Next, the impact of independent variables on the variables above was examined. At first, the crosstabulation of "sex" was examined, and this showed that there is a tendency on behalf of boys to have more frequently a negative attitude towards their fellow students that belong to a different social group. All the crosstabulations are statistically significant, despite the fact that strong tendencies were not observed in 
any case. More specifically, regarding the question of "sex", the $34.4 \%$ of boys compared to the corresponding $24.6 \%$ of girls rarely have a negative attitude. In relation to the variable of "nationality", the answers show that boys again have a different point of view in a statistically significant way. In this case the difference is not limited only to one dimension; $26.9 \%$ of boys in comparison to the $22.7 \%$ of girls rarely have a negative attitude in relation to the factor of "nationality", and a significant percentage of $14.1 \%$ of the male students in comparison to the $12 \%$ of the female students often behave in this way. Finally, $6.8 \%$ of boys in comparison to the $3.4 \%$ of girls very often have a negative attitude $(x 2=234.454, \mathrm{df}=3, \mathrm{p}=0,002<\mathrm{a})$.

A differentiation between genders is observed also in the question about religion. Boys are observed to be more negative towards their fellow students with different religious attitudes $(x 2=9.684, d f=3$, $\mathrm{p}=0.021<\mathrm{a})$. The following table shows the frequencies analytically:

Table 7. Gender and attitude about religion

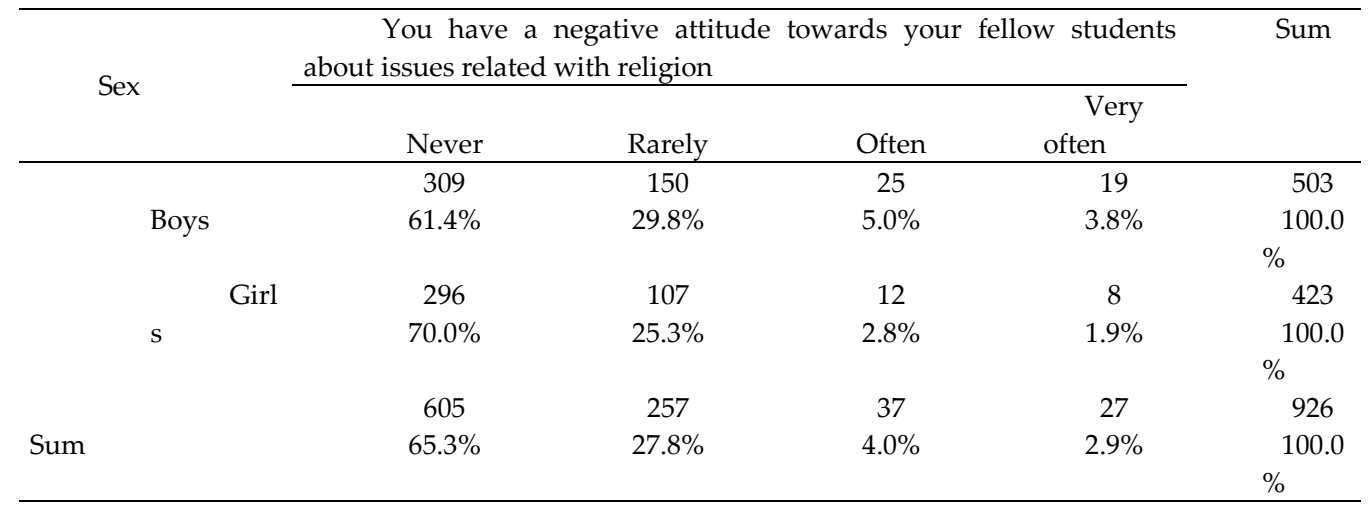

Again boys are observed to show a more negative attitude concerning different religion.

The analysis of the impact that some independent variables have on the students' attitudes continues with "urbanity". The results of all the crosstabs were found to be statistical significant. In specific, students from rural areas appear to have a stronger tendency towards higher level negative attitudes in all the topics discussed in comparison to the students from urban and semi-urban areas; in terms of the correlation between "urbanity" and "nationality" we observe that $32.5 \%$ of the students from rural areas often have a negative attitude compared to the corresponding $7.6 \%$ percentage of students who come from semi-urban areas and the $8.6 \%$ from urban areas. At this point we have to stress the fact that only $29.6 \%$ of the students from rural areas never had such an attitude in comparison to the corresponding $64.8 \%$ of students from urban areas and the $62.2 \%$ from urban areas $(x 2=112.962 . \mathrm{df}=6 . \mathrm{p}=0.000<\mathrm{a})$. The graph below shows the frequencies described above:

Graph 4. Urbanity and attitudes about different nationality.

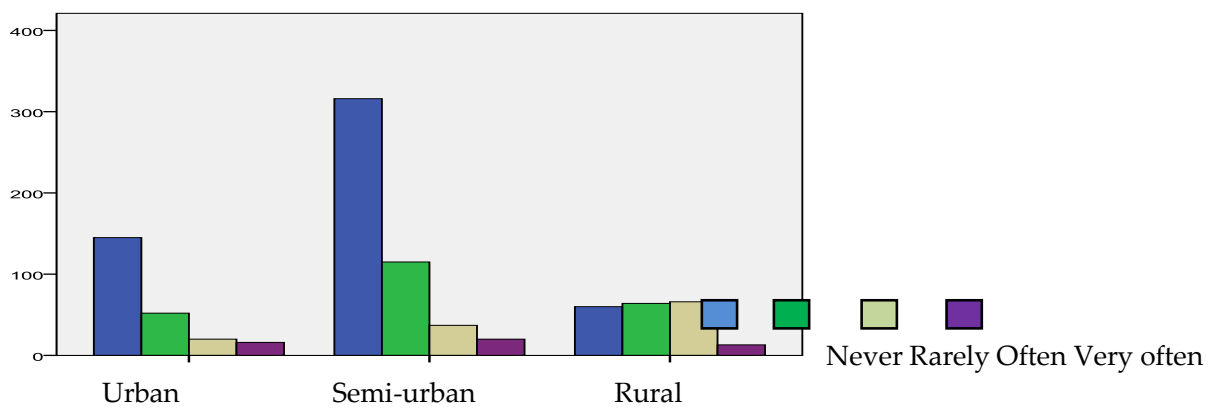

In addition, students from rural areas differentiate themselves as far as the question about attitude towards different gender is concerned. In this case $71.3 \%$ of students from rural areas rarely have a negative attitude in comparison to the $18.3 \%$ and the $18.6 \%$ percentages of students from semi-urban and urban areas respectively $(\mathrm{x} 2=212.180, \mathrm{df}=6, \mathrm{p}=0.000<\mathrm{a})$. Moreover, the $68.1 \%$ of the students from rural areas rarely demonstrate a negative attitude about different religious beliefs as compared to the corresponding $14.5 \%$ and $20.1 \%$ of the students from semi-urban and urban areas respectively $(x 2=223.087, \mathrm{df}=6, \mathrm{p}=0.000<\mathrm{a})$. 
Next, all the variables discussed in this paper (students' attitude on different origin, gender and religion) were connected in one hyper - variable. The Cronbach's alpha index is statistically significant $(0,744)$. Also its mean is 6.25 and its variance 5,975 . This hyper - variable was correlated with the final grade of the students. The result is statistically significant $(-0,162)$. showing that the higher is the grade the less is the existence of negative attitude towards the fellow students with a different point of view as far as the factors above are concerned ${ }^{2}$.

Table 8. Correlation matrix

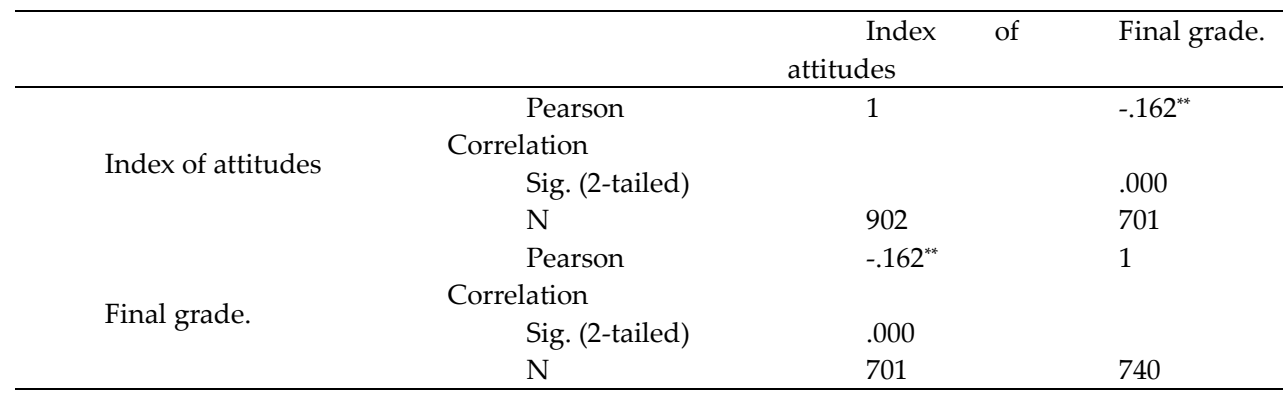

**. Correlation is significant at the 0.01 level (2-tailed).

Finally, the method ANOVA was used for the examination of the existence of statistical significant relations between the index of attitudes and the professional status of the students' parents. Professional statuses were grouped into three categories; low status professions (self-employed, civil servant in a low position and private employee in a low position), medium status (freelance, employer (up to 5 people), civil servant in a medium position and private employee in a medium position) and high status (Employer (more than 5 people), private employee in a high position and civil employee in a high position). The Kolmogorov Smirnov test was used in order to have the normality of the variables examined. The results show that there were all the prerequisites for using the ANOVA test. The results in both parents' cases were statistical significant $(\mathrm{F}=22.381, \mathrm{df}=8, \mathrm{p}=0.016<\mathrm{a})$ as far as father is concerned and $(\mathrm{F}=32.103, \mathrm{df}=8, \mathrm{p}=0.034<\mathrm{a})$ as far as mother is concerned. It is observed that students with parents, whose profession belong to the so-called low status category, have low values in this index whereas the opposite is observed in medium and high status categories. The same applies to students whose mothers belong to the same categories. Both graphs below depict the results for all the professional categories:

Graph 5. Relation between father' s profession and the index of attitudes.

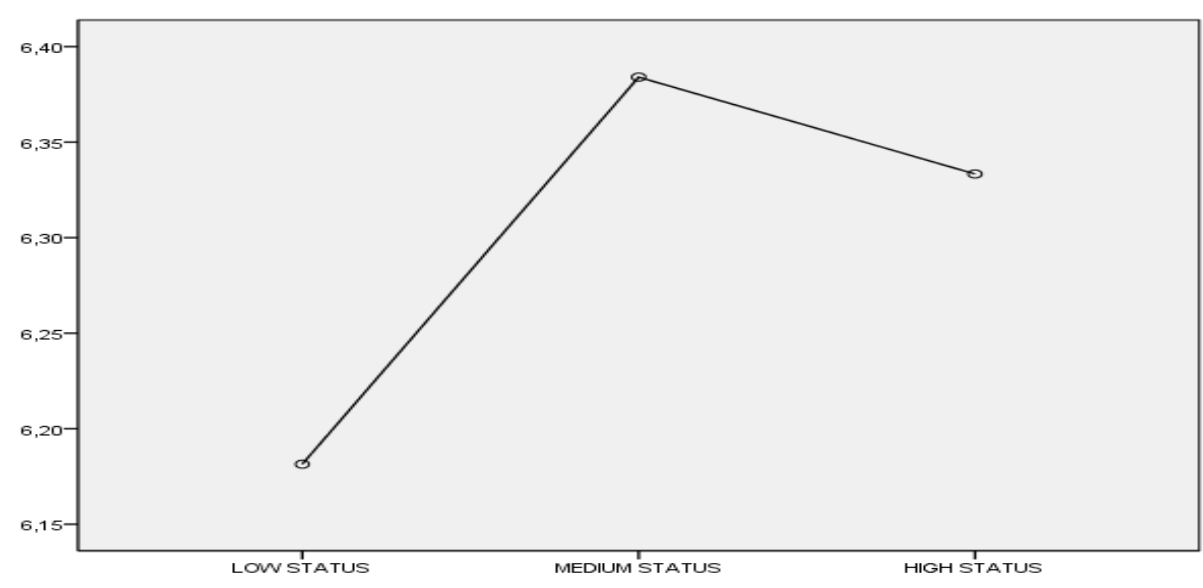

Graph 6. Relation between mother' s profession and the index of attitudes.

2 It has to be noted that in social sciences relatively low values can be used to show a statistical significant relationship between two variables (Kelpanides, 1999). 


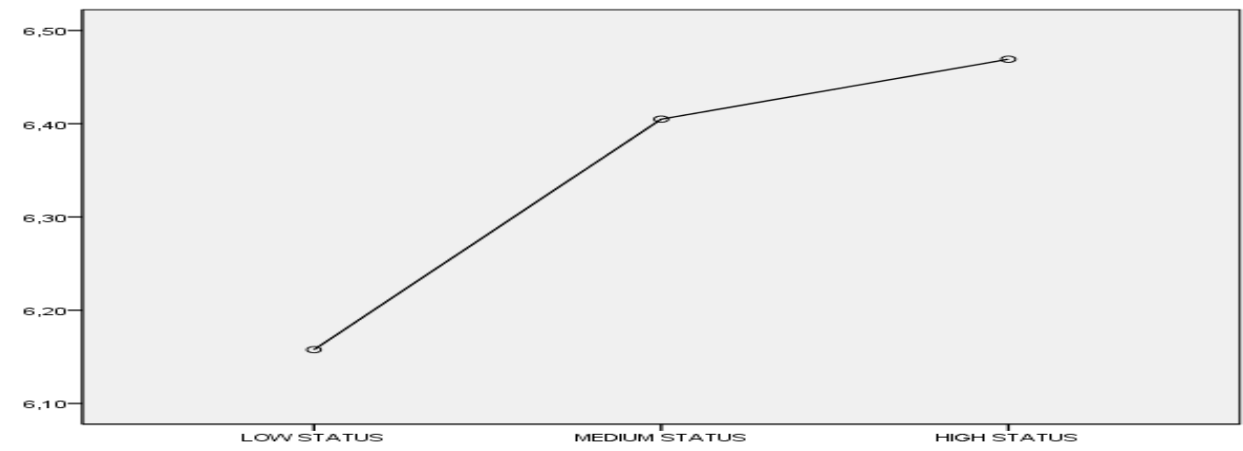

\section{DISCUSSION}

The acceptance or not of the "stranger" is a significant issue of nowadays, since one of the major characteristics of globalization is culture intermingling. This research deals with the presentation of the points of view of students according to issues that are related with their everyday life and are related to the "different". In order to analyze the data more effectively an index was created, since all the questions had a common measurement scale. In addition, internationally similar indexes have been created in similar questionnaires (Botsch, 2011 - Owen, 2008). What's more, the impact of independent variables was analyzed both in terms of the index itself and of each variable separately in order to find statistical significant correlations. One important finding of this research is that generally students do not have a negative attitude towards their fellow students according to issues that are related to different "origin", "sex", and "religion". A similar conclusion was also presented in the "EUROPE ON THE EDGE" survey which found that $74 \%$ of the respondents had a positive point of view about immigrants and about their having the same rights as the native population of the countries involved ${ }^{3}$. This fact correlates strongly with the positive attitudes on the importance of how much citizens should be active in a community. It has to be noted, though, that despite this general conclusion of the Greek research, some differentiations were observed between the sexes; the boys tend to show a more negative attitude in comparison to the girls.

Furthermore, a major conclusion of this research is the fact that students from rural areas have a far more negative attitude towards their fellow students in comparison to the students from semi-urban and urban areas. Finally, the students' general school performance seems to correlate negatively with the negative attitudes whereas differentiations are observed relating to the professional status of the parents. The tendencies that are put forward through the data analysis show that the socially dominant beliefs and stereotypes about their peers with different sex, origin and religion have begun to influence their cognitive horizon and have partially formed their field of conscience. Based on those data, this research aspires to make teachers think about the procedures of forming, diffusing and perpetualizing the stereotypes and the beliefs of society for everything different and to lead the way of forming a critical mind towards the negative beliefs and attitudes of some students in school. Also, it has to be taken into consideration that even though students and young people in general have a definite point of view about politics, they do not appear politically active in the traditional way; EUROPE ON THE EDGE survey showed that a low percentage of students and young people $(20 \%-27 \%)$ are actively involved in University or in sports clubs. The majority of the respondents in the survey are not involved, a fact that is connected with the disappointment of young people towards the traditional way of political participation (Norris, 2011).

The scope of this research was based on the impact of political socialization on students' conceptions about issues that are related to anything "'different'. The final conclusion is that although there are adversities, students appear to demonstrate ideals and principles that have remained unaltered in the Greek society, where tolerance is not the exception but the rule. The tendencies that were observed should be taken into consideration by the people that are assigned to make decisions and plan the educational policy of the country, so as to eliminate distortions that can become dangerous in the times we live in. For the time being, the refugee crisis in Syria has increased the number of people that seek refuge to Greece and its neighboring countries. It would be appropriate to keep on researching about students views on the "different" due to the

\footnotetext{
${ }^{3}$ http://www.sharingperspectivesfoundation.com/wp-content/uploads/surveystats.pdf
} 
fact that the new situation is quite different. The conditions now can be characterized as critical and it would be useful to learn about future citizens views on the possibility to accept or not to accept the "stranger", as a new factor has emerged, that of compassion.

\section{References}

Almond, G. \& Verba, S. (1963). The civic culture: Political attitudes and democracy in five nations. Princeton. N.J: Princeton University Press. 94-108.

Beck, P. A., \& Jennings, M. K. (1982). Pathways to participation. American Political Science Review. 76,

Botsch, R. (2011). The 2011 USCA Student Political Socialization Survey: An Initial Overview. http://www.usca.edu/polisci/SSBRLab

Demertzis, N. \& Stayrakakis, J. (2008). Youth: the imponderable factor. Athens: Polytropon (in Greek).

Gimpel, J., Lay. J. C., \& Schuknecht, J. E. (2003). Cultivating Democracy: Civic environments and political socialization in America. The Brookings Institution. Washington, DC.

Givalos, M. (2005). Political Socialization and educational environment. Athens: Nisos (in Greek).

Gotovos, A. (2004). Students with cultural alienation: Experiences. conceptions and attitudes towards the difference. Ioannina (in Greek). http://repository.edulll.gr/edull1/retrieve/1679/299.pdf Montpelier.

Inglehart, R.. (1990). Culture Shift. Princeton. N.J.: Princeton University Press, James Madison' s

Kelpanides, M. (1999). Methodology of pedagogical research with statistics, Thessaloniki, Codex publications (in Greek).

Marshall, G. (1998). Dictionary of Sociology (2nd ed). Oxford: Oxford University Press.

Metaxas, A. (1976). Political Socialization. Athens: Applied Political Science. (in Greek)

Norris, P. (2011) Democratic Deficit: Critical Citizens Revisited, New York: Cambridge University Press.

Sapiro, V. (2004). Not your parents' political socialization; Introduction for a new generation. Annual Review of Political Science 7: 1-23

Sherrod, L., Flanagan, C.. \& Youniss, J. (2002). Dimensions of citizenship and opportunities for youth development: The what. why. when. where. and who of citizenship development. Applied Development Science, 6(4,. 264-272.

Terlexis, P. (1975). Political Socialization: the genesis of political man. Athens: Gutenberg (in Greek). 